\title{
Knowledge, attitude and practice of dental students, practitioners and specialist on composite shade matching in Al-jouf, KSA
}

\author{
Mazen N. Alruwaili, Abdulkarim O. Alanazi, Rakan M. Albilasi, Yunus K. Alruwaili, Adel H. Alanazi, \\ Faisal F. Almusieb \\ Department of Endodontics, College of Dentistry, Al-jouf University \\ Corresponding author: Mazen nafa alruwaili, E-mail: Mzmilan8@ gmail.com, Tel. +966 501795407
}

\begin{abstract}
Background: Shade selection is an essential system to give patients an aesthetics renovation that correspondently merges to the patient's current dentition. Moreover, natural teeth are acknowledged to have various shades in their surfaces.

Objective: The aim of the study was to evaluate the awareness of knowledge, attitude and practice about the complications in shade selection and to utilize for improving the quality of training being imparted in the dental school and general practitioners.

Methods and Material: Participants were divided into six Groups: operative dentist and endodontist, 3rd Year students, 4th Year students, 5th Year students, Intern and VI-General practitioners; 20 Questionnaire survey forms were distributed to fill among all the groups.

Results: The results that the highest proportion was $41 \%$ for skill factor, knowledge was the second with $26 \%$. Whilst, individual observer was $13.5 \%$ and $12.6 \%$ for the factor talent. $4.5 \%$ for (All) the factors. The lowest proportion was for more than two answers.

Conclusion and Recommendation: The need of flourishing of cosmetic dentistry required to keep with up-todate information considering all conceivable factors which influence shade selection.
\end{abstract}

Keywords: Shade selection, Factors, Knowledge

\section{INTRODUCTION}

Nowadays, aesthetics has turned into an essential issue, as it appears to characterize one's character. Before, practical needs were the primary thought in dental treatment. Today, with the declining in caries pervasiveness, the concentration has moved toward dental Aesthetics ${ }^{(1)}$.

Furthermore, shade selection is an essential system to give patients an aesthetics renovation that correspondently merges to the patient's current dentition. Moreover, natural teeth are acknowledged to have various shades in their surfaces ${ }^{(2)}$.

The determination of teeth with an appropriate shade has been appeared to decidedly impact the patient's aesthetics observation and enhanced prosthesis acceptance ${ }^{(3)}$.

The determination of fake teeth shading can be extremely entrusting and denture aesthetics has been characterized as the cosmetic impact created by a dental prosthesis which influences the alluring magnificence, character, attractiveness and self-confidence of the person ${ }^{(4)}$.

\section{OBJECTIVE}

The aim of the study was to evaluate the awareness of knowledge, attitude and practice about the problems in shade selection and to utilize for improving the quality of training being imparted in the dental school and general practitioners.

\section{MATERIALS AND METHODS}

This is a cross-sectional of a qualitative approach. Participants were divided into six Groups:

I- Operative dentist and pedodontist,

II- 3rd Year students,

III-4th Year students,

IV-5th Year students,

V-Intern

VI-General Practioners

20 Questionnaire survey forms were distributed to fill among all the groups. Furthermore, data were collected for two months and one month for statistical analysis. It was done using ANOVA testand results were evaluated respectively.

\section{RESULTS}

The present study enrolled 105 candidates, from both gender male $(63, \% 60)$ and female (42, $\% 40)$. Age groups were (18-25) \%62, (26-35) \%35, (36-45) \%3 Ages were varied according to the level of education (high school, college, graduated). Table1 illustrates all the information collected of the socio-demographic characteristics of the candidates. 
Knowledge, attitude and practice of dental students, practitioners ...

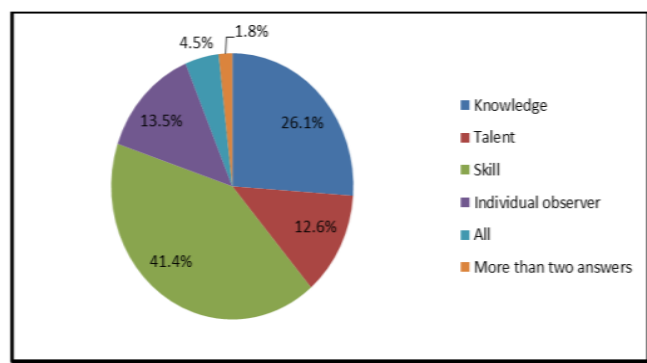

Figure (1): The essential factors for shade selection: Figure 1 indicates the essential factor for data shade selection. The highest proportion was $41 \%$ for skill factor, knowledge was the second with $26 \%$. Whilst, individual observer was $13.5 \%$ and $12.6 \%$ for the factor talent. $4.5 \%$ for (All) the factors. The lowest proportion was for more than two answers.

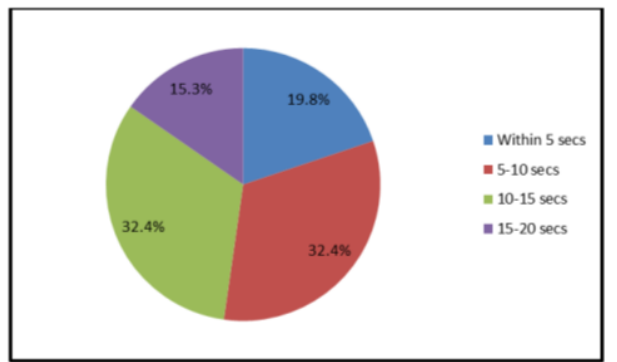

Figure (2): Ideal time required for shade selection: Figure 2 shows the ideal time required for shade selection. Firstly, there was identical proportion for both answers (10-15 secs) and (5-10 secs) $32.4 \%$. Moreover, $19.8 \%$ for (within 5 secs) and $15.3 \%$ for (15-20 secs).

Table1. Survey questionnaire.

\begin{tabular}{|c|c|}
\hline Questions & Results \% \\
\hline $\begin{array}{l}\text { Shade guide do you use commonly for composite shade selection } \\
\text { A] According to availability of shade guide } \\
\text { B] Only supplied by the company manufacturing that composite material } \\
\text { C]None }\end{array}$ & $\begin{array}{l}69.4 \% \\
22.5 \% \\
8.1 \%\end{array}$ \\
\hline $\begin{array}{l}\text { If shade of tooth is not matching with the shade guide, you make a custom shade guide by mixing two or more } \\
\text { available shades } \\
\text { A] YES } \\
\text { B]NO } \\
\text { C]No knowledge about this }\end{array}$ & $\begin{array}{l}52.3 \% \\
30.6 \% \\
17.1 \%\end{array}$ \\
\hline $\begin{array}{l}\text { Selection of the shade according to age/ gender of the patient } \\
\text { A] Yes } \\
\text { B] No }\end{array}$ & $\begin{array}{l}74.8 \% \\
25.2 \%\end{array}$ \\
\hline $\begin{array}{l}\text { The most common shade you use in your practice } \\
\text { A] A1 } \\
\text { B] A2 } \\
\text { C] B1 } \\
\text { D] B2 } \\
\text { E] Combinations of color if so (what are the colors you use?) }\end{array}$ & $\begin{array}{l}26.1 \% \\
12.6 \% \\
41.4 \% \\
13.5 \% \\
4.5 \%\end{array}$ \\
\hline $\begin{array}{l}\text { Method of isolation do prefer while doing shade matching for anterior restoration } \\
\text { A] Rubber Dam Isolation } \\
\text { B] Cotton rolls and Absorbent wafers } \\
\text { C] Teflon Tape } \\
\text { D] Evacuator system \& saliva ejector }\end{array}$ & $\begin{array}{l}41.4 \% \\
45.9 \% \\
3.6 \% \\
7.2 \%\end{array}$ \\
\hline $\begin{array}{l}\text { Method you prefer during shade selection } \\
\text { A] Visual (manual) } \\
\text { B] Instrumental (mechanical) } \\
\text { C] Combination of both }\end{array}$ & $\begin{array}{l}56.8 \% \\
19.8 \% \\
23.4 \%\end{array}$ \\
\hline $\begin{array}{l}\text { If manual, type of light would you do shade selection } \\
\text { A] Dental Light } \\
\text { B] Fluorescent light } \\
\text { C] Natural daylight (If so what time do u prefer?) } \\
\text { D] Natural and Dental Light } \\
\text { E] Natural Light and fluorescent light } \\
\text { D] Without light focus }\end{array}$ & $\begin{array}{l}32.4 \% \\
5.4 \% \\
21.6 \% \\
19.8 \% \\
6.3 \% \\
14.4 \% \\
\end{array}$ \\
\hline $\begin{array}{l}\text { According to you which is the best time for shade selection- } \\
\text { A] Morning time } \\
\text { B] Afternoon time } \\
\text { C] Day light from north } \\
\text { D] Don't follow a particular time for shade selection }\end{array}$ & $\begin{array}{l}48.6 \% \\
17.1 \% \\
11.7 \% \\
22.5 \% \\
\end{array}$ \\
\hline $\begin{array}{l}\text { How many times do you check the shade before deciding the final shade } \\
\text { A] Only once } \\
\text { B] } 2 \text { times } \\
\text { C] More than } 2 \text { times }\end{array}$ & $\begin{array}{l}36 \% \\
44.1 \% \\
19.8 \%\end{array}$ \\
\hline $\begin{array}{l}\text { Distance you keep between the patient's teeth and observer's eye during shade selection } \\
\text { A] Less than } 1 \text { feet } \\
\text { B] Between } 1-2 \text { feet } \\
\text { C] } 3 \text { feet } \\
\text { D] More than } 3 \text { feet }\end{array}$ & $\begin{array}{l}27.9 \% \\
43.2 \% \\
12.6 \% \\
16.2 \%\end{array}$ \\
\hline $\begin{array}{l}\text { Part of tooth would you prefer for the shade selection } \\
\text { A] Incisal } 1 / 3 \mathrm{rd} \\
\text { B] Middle } 1 / 3 \mathrm{rd} \\
\text { C] Cervical } 1 / 3 \mathrm{rd} \\
\text { D] All surfaces of the tooth }\end{array}$ & $\begin{array}{l}7.2 \% \\
25.2 \% \\
7.2 \% \\
60.4 \% \\
\end{array}$ \\
\hline
\end{tabular}




\section{DISCUSSION}

Our study focused on the degree of the knowledge and practice of dental student on an important issue which the composite shade matching. In esthetic dentistry, shade selection is most important to give natural appearance to the tooth ${ }^{(5)}$. Many factors are responsible. Figure 1 indicates the essential factor for data shade selection. the highest proportion was $41 \%$ for skill factor, knowledge was the second with $26 \%$. Whilst, individual observer was $13.5 \%$ and $12.6 \%$ for the factor talent. $4.5 \%$ for (All) the factors. The lowest proportion was for more than two answers. Here in our study the highest rate goes to Skill in comparison with other study that that individual observer $49.1 \%$ has the highest rate ${ }^{(6)}$.

Besides, color is one of the most significant factors of esthetic dentistry bearing in mind various factors such as form and intensity of the light foundation, time of day and year, angle of incidence, and patient's age, and sex gender ${ }^{(5)}$. Base on that, our results corresponded with the fact that gender and age affected the shade selection with proportion of $74.8 \%$ which approximate other study result $(82.5 \%)^{(6)}$.

Moving on the Shade guide used commonly for composite shade selection, the highest proportion was $69.4 \%$ for the availability of shade guide and $22.5 \%$ for the supplied company manufacturing that composite material. The common she used in practice is B1 with highest rate of $41.4 \%$. Our study results are not in agreement with those that showed that $\mathrm{A} 1$ have the uppermost proportion $66.2 \%$. Other factor that affects the shade selection is the light, yet is the most ignored one. In our results, dental light has the uppermost proportion to be used in shade selection $32.4 \%$. Therefore, quality of light is the most significant factor in shade taking practice ${ }^{(6)}$.

Additionally, participants were asked about the methods used during shade selection, the highest rate goes to visual (manual)56.8\%, instrumental (mechanical) $19.8 \%$ and $23.4 \%$ for the choice (combination of both). Other study conducted for the visual method with proportion of $59.6 \%$ approximately with our current study ${ }^{(6)}$. Although, $45.9 \%$ of the candidates used Cotton rolls and Absorbent wafers, $41.4 \%$ for Rubber dam isolation, $7.2 \%$ for Evacuator system \& saliva ejector, yet only $3.6 \%$ for Teflon Tape. It is important to mention that in shade selection; these are used for the conservative esthetic renovations which are perhaps the most significant part ${ }^{(7)}$. On the other hand, other study has revealed that $22.8 \%$ of people used as rubber dam isolation whereas $36.8 \%$ of them favored the use of cotton rolls and absorbing points, yet $15.8 \%$ of them frequently use Teflon tape ${ }^{(6)}$.

When we consider the ideal time required for shade selection, there was identical proportion for both answers (10-15 secs) and (5-10 secs) $32.4 \%$. Moreover, $19.8 \%$ for (within 5 secs) and $15.3 \%$ for (15-20 secs).

Moreover, our candidates attempted that (morning time) is the best time for shade selection with proportion of $48.6 \%$ and $44.1 \%$ for checking the shade before deciding the final shade 2 times. If we ever talk about the distance between the patient's teeth and observer's eye during shade selection, participants chose Between 1-2 feet $43.2 \%$. All surfaces of the tooth are the preferred part for them with proportion of $60.4 \%$.

\section{RECOMMENDATION AND CONCLUSION}

Color or shade which is of paramount importance should not be ignored as there is an increasing awareness and demand for esthetics by the patient. The topic of shade selection should be given due importance in the dental teaching practice and continued education programs should be arranged. Indeed, due to the flourishing of cosmetic dentistry, dental schools do not perform acceptable training regarding color education ${ }^{(8-9)}$. It is obligatory to perform adequate training programs as well as intensifying communication to reach to the satisfaction outcomes of shade matching. Besides, dentists should keep with up-todate information considering all conceivable factors which influence shade selection.

\section{REFERENCES}

1. Vaibhav NA and Jinesh AD (2010): Effect of light intensity on the shade selection in ceramic restorations: A survey. International Journal of Dental Clinics, 2 (3):23-26 
2. Rishita A. Jaju et al (2010): Evaluating Tooth Color Matching Ability of Dental Students of Dental Education. http:// www. jdentaled. org/ content/74/9/1002

3. Fernendes A, Fernandes A, Lakhani $D$ and Herekar M (2011): A survey on variability in shade selection by practicing dentists. Eur $\mathbf{J}$ Esthet Dent., 6(2):198-204

4. Vigneshwar T Sambandam M, and Sindhu R (2017): Knowledge, attitude, and practice of dental students and practitioners on shade matching of anterior teeth. Journal of Advanced Pharmacy Education \& Research, 7(3): 367-370

5. Marcucci B (2003): A shade selection technique. J Prosthet Dent., 89:518-21.

6. Dagg H, O'Connell B, Claffey N, Byrne D, Gorman C (2004): The influence of some different factors on the accuracy of shade selection. J Oral Rehabil., 22:900-4
7. Charbeneau G (1988): Direct esthetic restorations. In: Principles and Practice of Operative Dentistry. Philadelphia, PA: Lea and Febiger., http:// www. jopdentonline. org/ doi /pdf $/ 10$.2341 /1559-2863-18-3-1?code=opdtsite

8. Sproull R (1967): A Survey of Color Education in the Dental Schools of the World. http:// www.dentistrytoday.com/aesthetics/247-sp-2014354136

9. Pensler A (1995): What you were not taught about shade selection. Dent Econ., 85:80-1. 